\title{
DESINTERESSE DE APRENDER: UM ESTUDO COM OS JOVENS DO ENSINO MÉDIO DO MUNICÍPIO DE CONTENDAS DO SINCORÁ - BAHIA
}

\author{
Milena da Trindade Gomes ${ }^{1}$ \\ Maria do Amparo Oliveira Brito ${ }^{2}$
}

\section{RESUMO:}

Este estudo tem por objetivo analisar o desinteresse dos jovens em aprender os conteúdos curriculares propostos para o Ensino Médio do município de Contendas do Sincorá - Bahia. Para a efetivação deste trabalho, amparamo-nos em uma abordagem quali-quantitativa, portanto, esta possui um caráter exploratório e descritivo. Trata-se de um estudo de caso, com o instrumento de coleta de dados, utilizamos dois questionários, os quais foram respondidos por 209 (duzentos e nove) alunos, 11 (onze) professores e 1 (um) diretor. Após, a análise dos dados ficou evidente alguns fatores que interferem no interesse dos estudantes em aprender: a falta de estrutura física e tecnológica foi apontada enquanto fator desmotivante para o estudo, uma vez que impossibilita criar novas oportunidades aos discentes e torna as aulas desinteressantes. A desvalorização e carga horária de trabalho excessiva de alguns professores também foram apontadas, pois estes empecilhos dificultam o empenho desses profissionais, tornando-o insuficiente para incentivar os educandos a estudar. Além destes, a falta de apoio familiar para que os jovens consigam perceber a relevância dos estudos, a falta de um projeto de vida a ser alcançado e o fato de não possuírem o hábito de estudar para aprender são apontados por essa pesquisa também como aspectos que desanimam os discentes a se interessarem pelos estudos. Esses fatores indicam a necessidade em pensar sobre alternativas eficientes que promovam a vontade e aprendizagem do educando.

Palavras-chave: Ensino Médio. Desinteresse. Discentes.

\footnotetext{
1 Mestranda em Educação pela Facultad Interamericana de Ciencias Sociales. Asunción-PY. E-mail: milenatrindade190@outlook.com. Telefone: (77) 99199-5767.

2 Mestranda em Educação pela Facultad Interamericana de Ciencias Sociales. Asunción-PY. E-mail: amparocba@yahoo.com.br. Telefone: (77) 98115-4741.
} 


\section{INTRODUÇÃO}

O cotidiano escolar tem sido marcado pelo desinteresse dos alunos em aprender, principalmente os conteúdos abordados nas disciplinas que fazem parte do currículo do Ensino Médio. Com isso, a escola tem encontrado dificuldade em cumprir seu papel social de educar os jovens que dela fazem parte, no intuito de promover a eles aprendizagem e desenvolvimento cognitivo.

O Ensino Médio é a última etapa da educação básica e tem como objetivo preparar o discente para o desenvolvimento profissional, o ensino superior e sua formação integral enquanto indivíduo. Essa modalidade de ensino é constituída por um leque de disciplinas que contemplam as quatro áreas do conhecimento: Linguagens e suas Tecnologias, Matemática e suas Tecnologias, Ciências da Natureza e suas Tecnologias e Ciências Humanas e Sociais Aplicadas.

Essas áreas do conhecimento, em consonância com um suporte pedagógico e com uma estrutura física e tecnológica adequadas, devem proporcionar aos alunos a sua formação básica para que, assim, consigam sucesso na opção de carreira desejada.

Deste modo, o aluno tem a oportunidade de aprender as diversas áreas do conhecimento e escolher o curso técnico ou superior que mais se identifique. Mesmo não desejando continuar os estudos, espera-se que o estudante tenha formação básica suficiente para conseguir um emprego digno após a conclusão desta etapa do ensino.

Sendo constituída desta maneira, a educação básica e principalmente o Ensino Médio têm enfrentado dificuldades quanto à preparação de seus educandos, pois estes costumam estar desinteressados pela aprendizagem escolar. Notamos isso quando observamos o elevado quantitativo de alunos que fazem a avaliação final ou são reprovados e ainda há os desistentes.

Sabemos que as escolas públicas brasileiras têm encontrado obstáculos quanto à oferta e manutenção de suporte pedagógico e infraestrutura de qualidade, porém, mesmo diante destas dificuldades, percebemos em alguns alunos a persistência, não se deixam desanimar e conseguem sucesso em seu percurso no Ensino Médio.

Pensando nos alunos desistentes, nos que fazem a avaliação final, nos reprovados e nos que chegam a repetir até três anos da mesma série, decidimos investigar a seguinte questão: quais os principais fatores e quais colaboram para o desinteresse escolar dos alunos do Ensino Médio de Contendas do Sincorá - Bahia? A partir deste questionamento base, suscitamos outras perguntas de pesquisa, tais quais: a escola tem conseguido atender às 
expectativas dos jovens para o Ensino Médio?Os jovens que estão na escola possuem um projeto de vida definido?Quais os fatores de desinteresse dos jovens em estudar?A família destes jovens os estimula a estudar?

Considerando os questionamentos supracitados, entendemos que, no processo de motivação para a aprendizagem, a atenção tem um papel importante, pois, por meio dela o conhecimento é internalizado pelo indivíduo. Não é possível entender, muito menos aprender, algo que não tenha sido motivo de atenção.

Assim sendo, as pessoas dedicam suas atenções e são motivadas a aprender sobre o que lhes despertam interesse, o que lhes fazem sentido, e, dessa forma, modificam as suas vidas. Ao pensarmos na escola como um ambiente favorecedor da aprendizagem, decidimos investigar quais os principais fatores que contribuem para o desinteresse escolar dos alunos do Ensino Médio de Contendas do Sincorá-BA.

O desinteresse dos alunos em aprender é notável quando observamos o rendimento escolar, em que muitos não alcançam a média mínima da escola, faltam às aulas excessivamente ou desistem de estudar.

Além disso, esta falta de interesse pelos estudos tem comprometido o desempenho dos estudantes, o que, consequentemente, terá impacto em suas vidas, no mercado de trabalho e no contexto sócio econômico do país.

Sendo assim, objetivamos, neste artigo, investigar os fatores que contribuem para o desinteresse escolar dos alunos do Ensino Médio de Contendas do Sincorá-Bahia. Para tanto, seguiremos as seguintes etapas: i) expor um breve histórico sobre o Ensino Médio no Brasil, ii) apresentar as principais características sobre a juventude que frequenta o Ensino Médio; e, iii) analisar a relação entre desinteresse de aprender e desempenho escolar.

\section{Breve Histórico da Educação no Brasil}

Para compreendermos a realidade e os desafios educacionais existentes no Brasil atualmente, é preciso conhecer o contexto no qual foi tecido o sistema escolar desde a sua implantação no Período Colonial.

O Ensino Médio foi constituído no Brasil ainda no período colonial pelos jesuítas, ficando sob sua responsabilidade do século XVI ao século XVIII. Os jesuítas trouxeram ao Brasil a moral, os costumes, a religiosidade e os métodos pedagógicos europeus. De acordo com Romanelli (1999), 
Foi a família patriarcal que favoreceu, pela natural receptividade, a importância de formas de pensamento e idéias dominantes na cultura medieval européia, feita através da obra dos Jesuítas. Afinal, ao branco colonizador, além de tudo, se impunha distinguir-se, por sua origem européia, da população nativa, negra e mestiça, então existente, A classe dominante, detentora do poder político econômico, tinha de ser também detentora dos bens culturais importados (ROMANELLI, 1999, p.33).

Nesse período, a educação tinha uma estrutura planejada e ligada ao catolicismo, o sistema educacional tinha o objetivo de cristianizar os índios que aqui viviam, com o intuito de obter mais fiéis para a igreja.

A educação não era oferecida apenas aos índios, os Jesuítas também formavam e educavam os filhos dos colonizadores, a diferença era que os indígenas recebiam uma educação de ler e escrever e os filhos dos colonizadores ler, escrever e instruir.

Este modelo de ensino perpetuou-se por mais de 200 anos, tendo fim em 1759, quando os jesuítas foram expulsos da colônia pelo rei de Portugal. Isso se deu em função das diferenças de objetivos do modelo de educação oferecido pelos religiosos com os interesses da corte.

Ao retirarem os Jesuítas do território brasileiro, a educação sofreu um desajuste.Não havia mais um modelo de educação. A educação até então era monopólio da igreja e esse monopólio é transferido para as mãos do Estado. A educação se torna de interesse público, é uma educação estatal, cabe ao estado pensar, organizar e estruturar o sistema educacional.

Um modelo educacional demorou a ser regulado e as tentativas de organização não chegaram nem próximo da educação oferecida pelos jesuítas. Criaram as aulas régias, as quais eram ministradas pelos "formados nos seminários dirigidos pelos Jesuítas, eles foram os naturais continuadores de sua ação pedagógica” (ROMANELLI, 1999, p.36).

Surge no Brasil, durante o Período Imperial, a primeira Constituição Federal em 1824, que organizava e dividia a responsabilidade quanto à oferta do ensino, ficando o ensino primário e secundário, que hoje é o Ensino Médio, sob os cuidados das províncias, e o ensino superior, da União.

Nesse período há uma carência de professores e por isso utiliza-se do método Lancaster, o qual aproveita os alunos mais desenvolvidos para servir de auxílio ou para substituir o professor. Cria-se também o imposto, um subsídio literário para pagamento do professor.

Os anos que seguiram após a Proclamação da República, em 1889, foram marcados por uma aspiração a modernização que vai atingir a educação. "Nesse período no sistema de 
ensino do Brasil pré-industrial não havia sido instituída a dualidade entre ensino e trabalho" (NOSELLA, 2002 apud BREMER; KUENZER, 2012, p.3).

O sistema educacional brasileiro sofreu grandes transformações com a revolução de 1930, liderada por Getúlio Vargas. Uma das principais mudanças foi a criação do Ministério da Educação e Saúde Pública, comandado pelo ministro Francisco Campo. Até então, a educação era de responsabilidade do departamento nacional de ensino, ligado ao ministério da justiça, já que não existia, no Brasil, um órgão do governo responsável exclusivamente pela educação.

Após a criação do ministério da educação, foi instituído em 1931 o Decreto n ${ }^{\circ} 19.890$, que teve como complemento o Decreto/Lei $n^{\circ} 4.244$ de abril de 1942, o qual criou a Lei Orgânica do Ensino Secundário.

Nesse período há uma substituição da concepção de educação tradicional leiga por uma educação nova, a chamada Escola Nova. Trazida ao Brasil por Fernando de Azevedo, Anísio Teixeira, Lourenço Filho e outros intelectuais, e divulgada como Manifesto dos Pioneiros, esse movimento renovou o ensino brasileiro, pois seus adeptos defendiam a escola única.

[...] escola única, que superaria a dualidade escolar pela integração da escola profissional ao sistema regular de ensino, que passaria a ser articulada à formação secundária. Tendo por base os princípios da laicidade, obrigatoriedade, gratuidade e co-educação tal proposta não considerava as diferenças de origem econômica. Neste sentido, todos deveriam ter direito,dos 7 aos 15 anos, à mesma educação básica ofertada por uma escola única, oficial e pública, que considerasse suas aptidões individuais e biológicas (BREMER;KUENZER, 2012 p.4).

Em 1961, é promulgada a primeira Lei de diretrizes e Bases da Educação, de $\mathrm{n}^{\circ}$ 4.024/1961. Essa lei trouxe mudanças significativas para a educação e uma delas foi o reconhecimento e a "integração completa do ensino profissional ao sistema regular de ensino, estabelecendo-se a plena equivalência entre os cursos profissionais e propedêuticos, para fins de prosseguimento nos estudos" (KUENZER, 2007, p. 29).

Algumas transformações importantes aconteceram na educação a partir da Constituição Federal de 1988. A educação passa a ser um direito de todos e dever do Estado e da família, e o acesso ao ensino passa a ser obrigatório e gratuito. De acordo como art. 205 da Constituição Federal de 1988:

A educação, direito de todos e dever do Estado e da família, será promovida e incentivada com a colaboração da sociedade, visando ao pleno desenvolvimento da pessoa, seu preparo para o exercício da cidadania e sua qualificação para o trabalho (BRASIL, 1988, p. 129). 
Foi estabelecido um Plano Nacional de Educação, o qual tem o objetivo de aumentar o nível de escolaridade da população, democratizar o espaço escolar e melhorar a qualidade do ensino.

\section{A juventude e o Ensino Médio}

No cotidiano escolar escutamos sempre dos profissionais da educação reclamações com relação aos jovens que frequentam a escola, estes estão cada vez mais desinteressados, rebeldes, desrespeitosos, não veem sentido na escola e não tem expectativas quanto ao futuro.

Quando nos dirigimos aos estudantes às queixas também acontecem a se referirem à falta de estímulo e sentido nas aulas ministradas na escola, conteúdos, os quais não fazem sentido, professores despreparados, espaço físico desestimulante. Os jovens estão na escola porque são obrigados ou porque precisam do certificado de conclusão do curso.

Neste sentido, ao tentarmos entender o que de fato tem acontecido com a escola, pois, seu desempenho não tem sido os melhores nos últimos tempos. Então, nos deparamos com diversos fatores apontados pelas pessoas envolvidas nesse processo e de pessoas externas. "Tem se tornado comum também que governos e "especialistas" em educação enxerguem no professor a origem da crise de qualidade e "desempenho da escola", na tentativa de encontrar um responsável por esse fracasso escolar." (CARRANO;DAYRELL, 2014, p.103):

[...]parece que assistimos a uma crise da escola na sua relação com a juventude, com professores, alunos e gestores se culpando mutuamente, perguntando a que ela se propõe. [...] a relação da juventude com a escola não se explica em si mesma: o "problema" não se reduz nem apenas aos jovens nem apenas à escola e aos seus professores. É fundamental superar nossa tendência em achar "o culpado" de um relacionamento problemático. (CARRANO; DAYRELL, 2014, p. 103).

O público anterior era homogêneo se tornou heterogêneo, e junto com as mudanças ocorridas na sociedade um novo perfil de estudante se apresenta para a escola. Assim, chega ao Ensino Médio pessoas oriundas de um contexto de grandes transformações sociais com necessidades próprias que não se adequam mais ao processo educativo baseado somente na transmissão de saber.

A partir dessas mudanças novas adversidades são postas a educação, além de se ocupar em instruir, a escola deve educar para a cidadania, para o acesso ao ensino superior e para o ingresso no mercado de trabalho. 
Nesse novo cenário, a escola perde a sua centralidade e já não é mais a única fonte de conhecimento, além disso, ela deve se ocupar também com outras dimensões tais como a formação humana e a autônoma do seu público.

Nesta perspectiva, há um desinteresse escolar dos estudantes pelos conteúdosdas disciplinas curriculares e pelas atividades escolares propostas, pois, esses alunos estão acostumados a um contexto urbano de múltiplas oportunidades de satisfação.

O desinteresse das atividades escolares promove uma perda por parte da escola do Ensino Médio de sua função social, esta enunciadora de significados e condutas para a formação do aluno, ocupando um lugar de passagem pelos estudantes desejosos de possuir requisitos mínimos para o mercado de trabalho ou conquistar o nível superior.

Estamos inseridos num mundo tecnológico, este diminuiu as distâncias e revolucionou o acesso as informações. São muitas notícias sendo transmitidas e disponibilizadas a todo tempo pelos meios de comunicação: rádios, TV, jornais, revistas, livros, celular, internet.

A internet é um meio de comunicação, o qual as informações são acessadas com muita rapidez e facilidade. Porém, nem todo dado disponibilizado por essa via tem veracidade. Além de ter conexão, as pessoas também podem disponibilizar conteúdos, e estes podem ser de qualidade ou não, verdadeiros ou não.

Não basta, para fazer uma pesquisa, dar uma googlada (grifo do autor), porque o Google é ponto de partida de uma pesquisa, não ponto de chegada. Ademais, os usuários desse mecanismo de busca devem cuidar de garantir a qualidade de suas pesquisas no cotidiano, mediante ações que são consideradas indispensáveis em ciências: a comparação com os pares, a verificação dos dados e da legitimidade das fontes. [...] sabemos o quanto ainda há de informação falsa e deturpada na rede mundial. (CORTELLA, 2011, p.82).

Além de informação a internet disponibiliza a seus internautas aplicativos extraordinários envolvendo a atenção dos indivíduos e principalmente dos jovens, tais com WhatsApp, Facebook, Instagram, Netflix, jogos e o YouTube, dentre outros.

Diante de todas as notícias e atrações disponibilizadas pelos meios de comunicação a escola parece ficar de certo modo longe dessa nova realidade, pois, as informações estão chegando aos jovens com tanta facilidade. O problema é que são muitas informações, mas nem sempre se pode garantir o conhecimento de modo eficaz, "porque informação não é conhecimento, é base para conhecimento (CORTELLA, 2011, p. 97).

Neste contexto, a escola pública perde a sua centralidade e a sua eficácia, pois os valores sociais mudaram as possibilidades de distrações e as tecnologias, as quais os alunos 
tem acesso fora da escola são mais atrativas do que os conteúdos e a forma com estes são ministrados na escola.

Outro fator, o qual não podemos deixar de destacar é os pais imputarem à escola a educar moral dos jovens, mas infelizmente não oferecem meios para isso, pois se estes não tem noção de hierarquia a partir do convívio família dificilmente ele conseguirá fazer isso nos outros ambientes de convivência, inclusive na escola. Por isso, estamos presenciando a falta de respeito dos alunos com os professores, e estes estão perdendo a sua autoridade.

\begin{abstract}
Ainda no âmbito das relações sociais que ocorrem no cotidiano escolar, é necessário ressaltar aquelas existentes entre alunos e professores. Vem ocorrendo uma mudança significativa nessa relação, principalmente na questão da autoridade, onde os alunos não se mostram dispostos a reconhecer a autoridade do professor como natural e óbvia. (DAYRELL, 2007,p.1121)
\end{abstract}

Isso ocorre porque esses jovens não reconhecem a autoridades de seus pais. $\mathrm{O}$ convívio com os colegas também se torna cada vez mais conflituoso por causa da forma egocêntrica, a qual são criados, tudo isso é o reflexo da educação recebida (ou não recebida) em casa.

Esses desafios indicam o quanto à educação precisa ser repensada, no intuito de fazer sentido e conseguir promover conhecimentos significativos para seu público, pois, as expectativas destes tem sido contrárias com a realidade oferecida pela escola.

Diante do exposto, faz-se necessário entender como a aprendizagem acontece, como esta vem sendo conduzida pela escola e a sua relação com a evolução do educando.

\title{
3 Desinteresse de aprender versus desempenho escolar: uma relação de interdependência
}

Este artigo é resultado de uma pesquisa realizada nas turmas do Ensino Médio de uma escola pública estadual localizada no município de Contendas do Sincorá, interior da Bahia. Trata-se de uma escola de pequeno porte, que atende nos três turnos: matutino, vespertino e noturno.

Com o objetivo de investigar os fatores que contribuem para o desinteresse escolar dos alunos da escola pesquisada realizamos uma pesquisa quali e quantitativa com os alunos do ensino médio matriculados no ano letivo de 2018, bem como com os professores atuantes nas referidas turmas atendidas na instituição. Conseguimos a colaboração espontânea de todos os envolvidos na pesquisa respondendo ao questionário e participando da entrevista estruturada, sendo 209 (duzentos e nove) alunos, 11 (onze) professores e 1 (um) diretor. 
Como instrumento de coleta de dados, escolhemos usar o questionário por se tratar de um recurso objetivo e compreensível quanto às demandas para a pesquisa, o que nos permitiria alcançar todo o universo pesquisado, mostrando-os a relevância da pesquisa e permitindo-os serem transparentes em suas respostas.

Destacamos, abaixo, parte dos dados coletados durante a pesquisa, com foco sobre os motivos que levam ao desinteresse do alunado.Vejamos, em seguida, o primeiro deles, no qual mostramos e discutimos a falta de uma rotina diária de estudos para além da cargahorária escolar.

Gráfico 1: Quantas horas você costuma estudar?

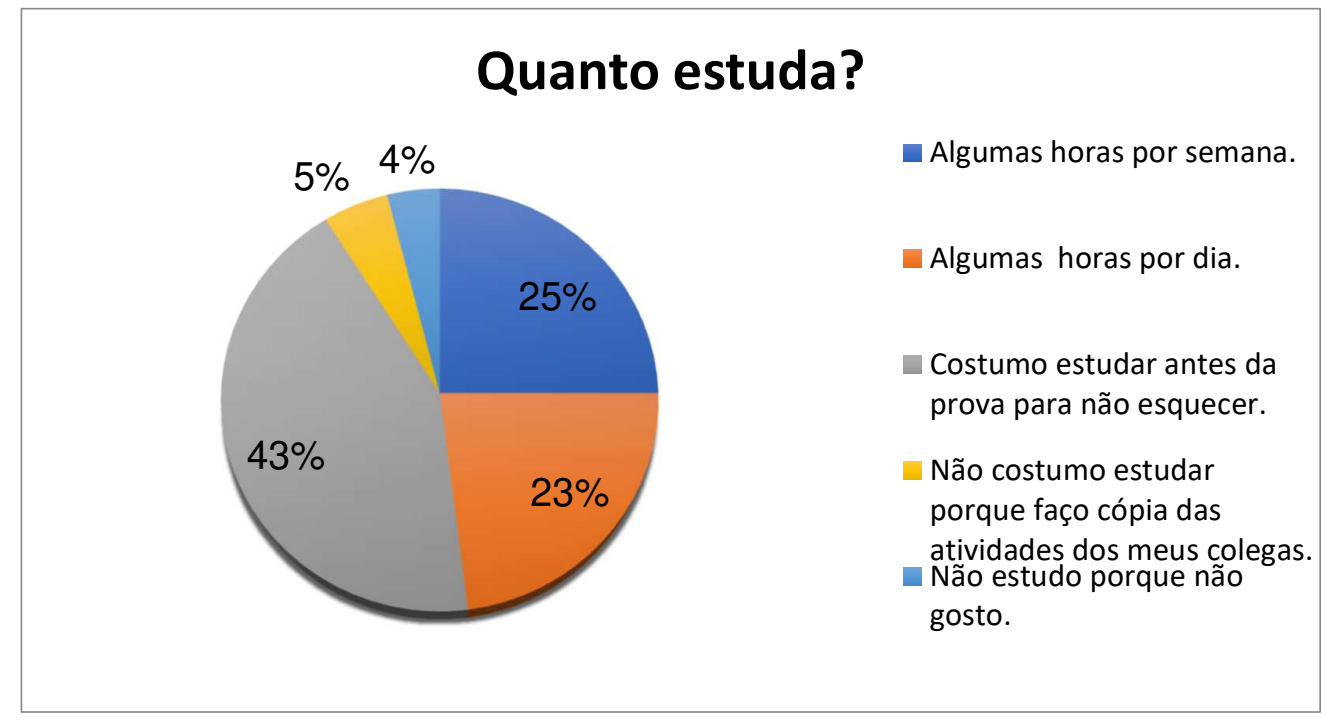

FONTE: Dados obtidos pela autora, 2018.

Questionados sobre o quanto estudam, 25\% dos discentes afirmam estudar algumas horas por semana, $23 \%$ algumas horas por dia, $43 \%$ costumam estudar momentos antes da prova para não esquecer, $5 \%$ admitem não estudar porque fazem cópia das atividades dos colegas e $4 \%$ responderam não estudar porque não gostam.

Se juntarmos a quantidade de alunos que estudam apenas na véspera das avaliações ou não estudam teremos $52 \%$, ou seja, mais da metade dos alunos não dão, ou não sabem a importância de dedicar um tempo do seu dia para estudar.

Com relação ao tempo que devemos dedicar estudando sozinhos os conteúdos que precisamos aprender. Para Piazzi:

Esta é a parte mais difícil. Se você entendeu que tem de estudar todo dia, já sabe "quanto" estudar:

Pouco!

- Mas quanto é esse pouco? Dez minutos, uma hora, cinco horas?

A resposta pode parecer estranha, mas é a que realmente funciona: 
Quanto?... Você vai descobrir. Ou seja,ao criar o hábito de estudar todo dia, você irá perceber, ao se autoavaliar algumas semanas depois, que houve dias em que estudou demais ("choveu nomolhado") e outros nos quais estudou de menos.

Em poucos dias ou, no máximo, em poucas semanas,você vai encontrar o ritmo correto(PIAZZI, 2008, p.49).

Assim, é mais importante a qualidade do estudo do que sua quantidade. Devemos estudar pouco, mas todos os dias e conforme formos nos habituando, entenderemos o quanto precisamos estudar.

No gráfico abaixo, destacamos os fatores determinantes para o desinteresse escolar, de acordo com as posições diretas por parte do alunado.

Gráfico 2: Em sua opinião, qual fator contribui para o desinteresse escolar dos discentes de sua escola?

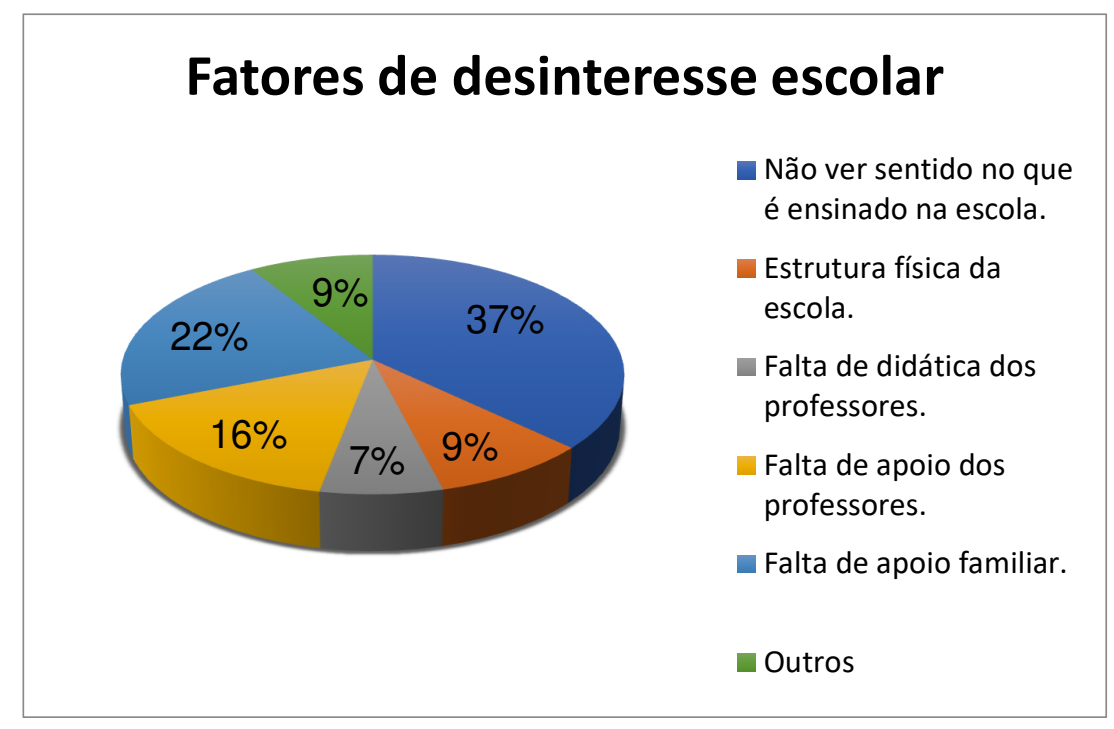

FONTE: Dados obtidos pela autora, 2018.

$\mathrm{Na}$ tentativa de responder a questão motora desse trabalho, perguntamos aos alunos, Quais são os fatores, os quais contribuem para o desinteresse escolar dos discentes de sua escola?

Os dados mostram que $37 \%$ dos alunos não vêem sentido nos conteúdos ensinado na escola, 9\% declaram que o problema é a estrutura da escola, 7\% apontaram a didática dos professores, $16 \%$ sentem falta de apoio dos professores, $22 \%$ dizem que é a falta de apoio familiar.

Os demais alunos, 9\%, admitem ser outros os fatores de desinteresse escolar e menciona o uso do celular, a conversa paralela em sala de aula, a preguiça, o cansaço por 
causa do trabalho, os colegas que não levam os estudos a sério ou não se importam em aprender.

A pesquisa revelou os fatores que mais interferem no interesse dos alunos em aprender o conteúdo ensinado na escola, e são: a falta de utilidade dos conteúdos ministrados nas aulas, e a falta de apoio dos professores e dos pais.

A falta de interesse escolar dos alunos pode estar diretamente ligada à próxima questão analisada. As metas traças pelos alunos, como objetivos de vida influenciam em seu empenho na escola, por isso, perguntamos $\mathrm{O}$ que pretendem fazer quando terminarem o Ensino Médio?

Gráfico 3: O que pretende fazer após terminar o Ensino Médio?

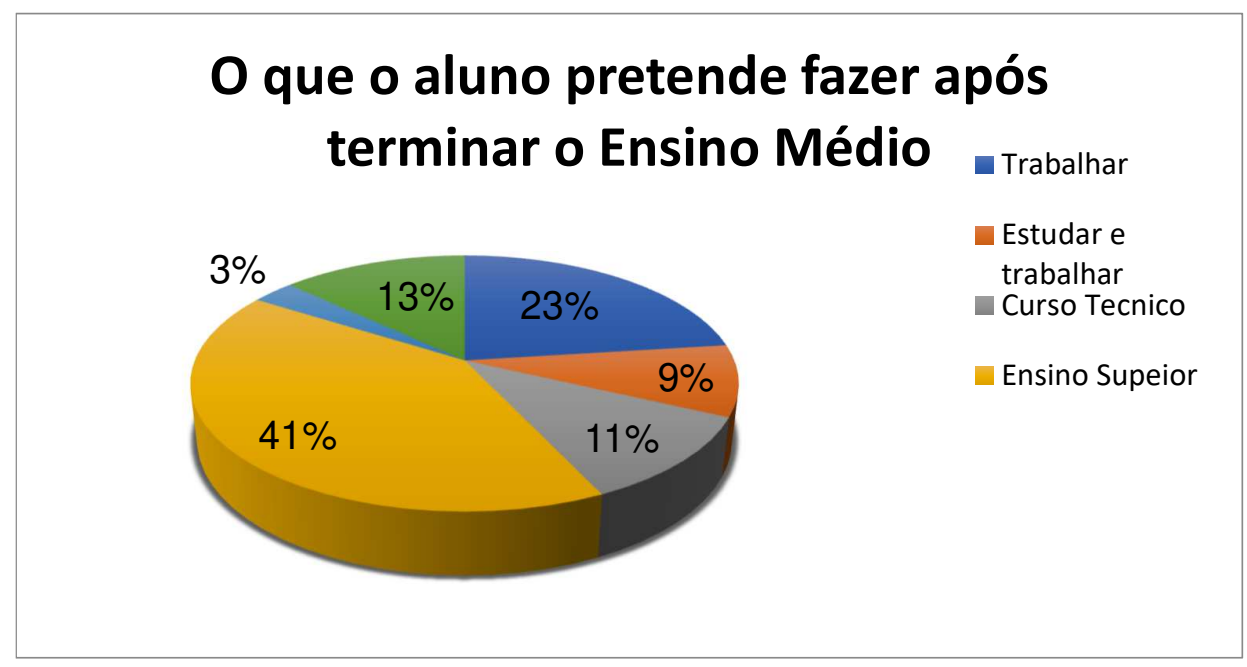

FONTE: Dados obtidos pela autora, 2018.

A maioria dos alunos, $41 \%$, pretende fazer o Ensino Superior. Os cursos pretendidos são: odontologia, direito, ciências da computação, administração, medicina, engenharia elétrica, farmácia, jornalismo, psicologia, gastronomia, enfermagem. Na área da educação citaram matemática, educação física, letras e biologia.

Dos demais alunos, $23 \%$ querem trabalhar como caminhoneiro, músico, servir ao exército, polícia militar e federal e outros. $9 \%$ pretendem trabalhar e estudar, $11 \%$ desejam fazer um curso técnico, um cursinho pré-vestibular, futebol, mecânico, desenho e inglês.

Já os $16 \%$ restante, $13 \%$ não sabem o que querem fazer e $3 \%$ disseram não querer fazer nada, algumas afirmaram, serão donas de casa e outras que vão dormir.

Estudar e trabalhar estão entre os objetivos da maioria dos alunos pesquisados, porém, mesmo tendo suas metas definidas, os alunos em questão não estão motivados o suficiente a buscarem através do conhecimento meios de alcançar seus objetivos, afirmamos isso com 
base no alto índice de alunos que ficam na avaliação final ${ }^{3}$, e passam para a série seguinte com a ajuda do conselho de classe.

Gráfico 4: Avaliação discente para as aulas ministradas:

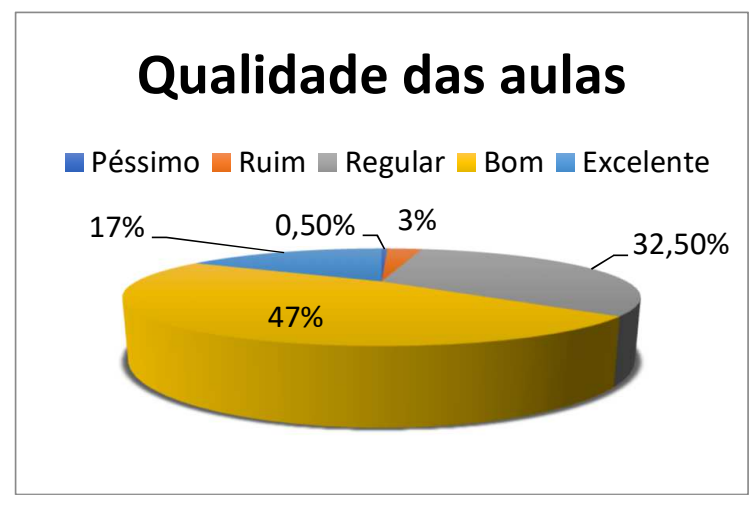

FONTE: Dados obtidos pela autora, 2018.

Com relação à qualidade das aulas ministradas na escola, 47\% dos alunos consideraram ser boas, $32,50 \%$ avaliaram como regular, $3 \%$ afirmaram ser ruins e $0,50 \%$ são péssimas.

Considerando os dados levantados em relação à qualidade das aulas, perguntamos, por outro lado, aos docentes qual era o seu empenho em preparar as aulas que lecionam. $\mathrm{O}$ resultado foi que $82 \%$ dos professores declararam ser bom e $28 \%$ afirmam que sua dedicação ao planejar as aulas é regular.

A pesquisa revelou ainda a insatisfação dos professores para com os seus proventos, $18 \%$ dos docentes afirmam ser insuficiente o valor que recebem pelo seu trabalho, $37 \%$ consideraram esse valor ser ruim, $18 \%$ acredita que é regular e $27 \%$ disseram ser bom.

As aulas são fundamentais no processo de ensino/aprendizagem. E, por meio delas, a escola vai desenvolver suas ações focando no desenvolvimento do educando.

A educação, a escola e o ensino são os grandes meios que o homem busca para poder realizar o seu projeto de vida. Portanto, cabe à escola e aos professores o dever de planejar a sua ação educativa para construir o seu bem viver (MENEGOLLA \& SANT'ANNA, 2001, p.11).

Neste sentido, é necessário que os professores definam os objetivos a serem alcançados em suas aulas e busque estratégias para isso. O planejamento é fundamental nesse processo e pode interferir em seus resultados.

${ }^{3} \mathrm{O}$ índice de repetência no Ensino Médio é mais acentuado na $1^{\mathrm{a}}$ série. Em 2018, dos 97 alunos matriculados na $1^{\mathrm{a}}$ série, $29 \%$ foram reprovados. Dos 56 alunos da $2^{\mathrm{a}}$ série, $6 \%$ foram reprovados. Na $3^{\mathrm{a}}$ série havia 56 alunos e $5 \%$ de reprovação. Diante do total de alunos desta unidade escolar, $16 \%$ foram reprovados, $40 \%$ foram aprovados pelo conselho de classe, $8 \%$ fizeram avaliação final e passaram, os demais $46 \%$ foram aprovados. 
[...] apesar do planejamento da ação educativa ser de suma importância, existem professores que são negligentes na sua prática educativa, improvisando suas atividades. Em consequência, não conseguem alcançar os objetivos quanto à formação do cidadão (CASTRO;TUCUNDUVA; ARNS, 2008. p.55).

A falta de planejamento é prejudicial às aulas, compromete a sua qualidade e a sua utilidade. Não apresenta sentido e nem proporciona aprendizado aos educandos.

Gráfico 5: Avaliação do acompanhamento familiar de seu desempenho discente:

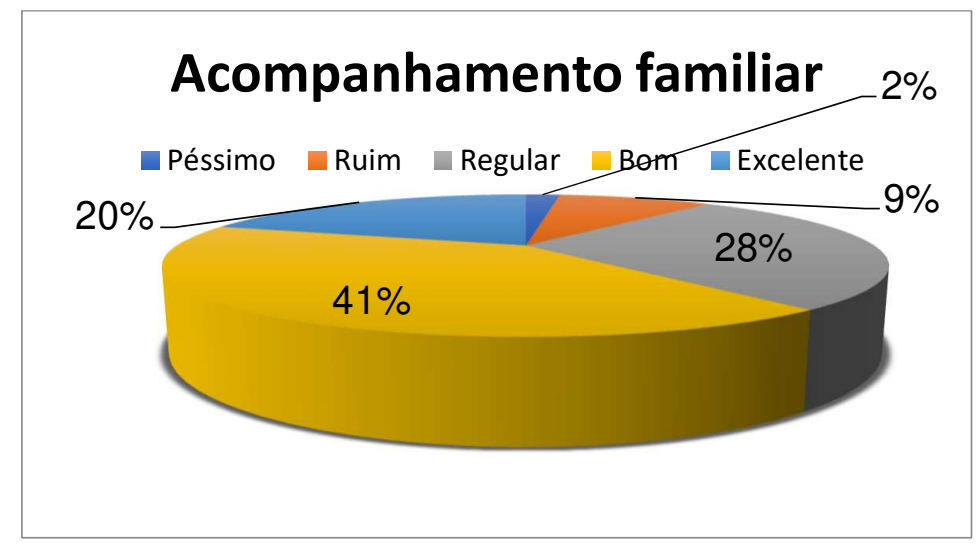

FONTE: Dados obtidos pela autora, 2018.

O acompanhamento familiar é muito importante para o desenvolvimento do educando. Questionados sobre a atenção que suas famílias dão ao seu desempenho na escola, $2 \%$ dos discentes disseram não serem acompanhados por seus pais, 9\% afirmou ser ruim, 28\% disseram que o acompanhamento da família na sua vida escolar é regular, $41 \%$ declarou ser bom e $20 \%$ reconheceu o excelente acompanhamento dos pais, ou seja, recebem apoio de seus pais para estudarem.

Já abordamos no primeiro capítulo sobre a importância do acompanhamento familiar ao educando para o seu desempenho na escola, cabe aqui ressaltar que os próprios alunos sentem essa necessidade e essa falta.

O desenvolvimento do educando é de responsabilidade da escola em conjunto com a família, pois esta é que deve dar suporte a escola no sentido de incentiva e acompanhar os passos dados por seus filhos.

Esse pode ser um dos fatores que tem contribuído significativamente para que os alunos estejam desinteressados da escola, pois, segundo os dados da pesquisa, a maioria dos pais e das mães tem baixo grau de instrução, além disso, muitos não acompanham e nem incentivam seus filhos a estudarem. 


\section{Considerações finais}

Mediante o estudo teórico e a análise dos resultados da pesquisa,compreendemos as razões, as quais colaboram para o desânimo dos estudantes em aprender o conteúdo escolar são diversas e complexas. Por isso, devido à amplitude e a significância da situação, não cabem neste momento das considerações finais, conclusões simplicistas.

Assim, ao longo da construção de todo o texto conclusões parciais foram sendo reveladas, de forma que o leitor pôde acompanhar, a cada seção, a condução e os resultados da pesquisa.

Neste momento, resta-nos, organizar esses resultados de modo a oportunizar uma visão global do que se desvendou dos dados, permitindo o reconhecimento dos objetivos traçados no início deste estudo.

Este trabalho permitiu analisarmos os motivos, os quais a educação pública tem se mostrado ineficiente, não tem feito sentido para a vida dos estudantes e os tem deixado desanimados a participarem ativamente desse processo educativo. Acreditamos que os resultados aqui encontrados sirvam de suporte aos educadores interessados em entender e provocar mudanças profundas o intuito de promover uma educação de qualidade a seus educandos.

Por meio dos resultados da pesquisa conseguimos perceber que a falta de uma estrutura física e tecnológica adequando tem contribuído para o desinteresse escolar dos discentes, pois o espaço escolar fica impossibilitado de inovar em seus métodos e oferecer um ambiente com maiores oportunidades a seus jovens.

Outro fator que está ligado ao primeiro são as aulas ministradas nesta unidade escolar, apontadas como sendo desinteressantes. Atribuímos a isso a falta de aparato tecnológico, somado aos desgastes, desvalorização e carga horária excessiva de alguns profissionais da educação.

A falta de incentivo e auxílio aos estudantes por parte de seus familiares, também é apontado nesta pesquisa como causador do desinteresse pelo estudo, uma vez que ainda são jovens e não possuem maturidade suficiente para si conduzirem sozinhos, assim faz-se necessários os genitores revelarem aos seus dependentes a importância dos estudos e acompanhá-los durante toda a trajetória escolar.

Foi possível perceber nos alunos matriculados na unidade de ensino pesquisada, os que possuem um projeto para sua vida a ser alcançado se empenham e aproveitam as oportunidades oferecidas pela escola como forma de alcançar suas metas. Já quem não possui um plano para a vida, no qual a educação não é o meio de conquistá-lo, não se sente motivado 
a se empenhar nas atividades oferecidas pela escola para se desenvolver cognitivamente, neste sentido consideramos que não possuir um projeto de vida é um dos fatores encontrados por esta pesquisa para que os jovens estejam desinteressados pelos estudos.

A forma como é conduzido o aprendizado na escola também se mostrou como sendo um dos fatores de desinteresse dos alunos pelo aprendizado escolar. A maioria dos alunos não possui o hábito de estudar, dificultando assim a efetivação da sua aprendizagem. Quando percebem que não estão aprendendo, e por isso não vêem suas vidas mudarem se sentem desmotivados a se empenharem na escola.

Percebemos também que o jovem do século XXI encontra-se em posição vantajosa tanto para o acesso dos bens de consumo quanto para o conhecimento. Assim sendo, os baixos níveis de rendimento escolar e a grande evasão se dão pelo não esforço mínimo em desempenhar uma atividade de longo prazo.

O imediatismo é matéria de primeira ordem e os jovens não conseguem entender que o estudo é um investimento duradouro, e esse caráter de tudo ser imediato reflete no campo de trabalho, pois estes jovens muitas das vezes sem qualificação encontram somente postos de trabalho, no qual o esforço físico é mais necessário que o mental, em detrimento disso abandona facilmente qualquer colocação que não corresponda a sua visão de mundo.

Assim sendo, essa pesquisa não se encerra nesse viés de análise, as possibilidades são diversas, pois, as mudanças estão ocorrendo e as visões para os processos de ensino e aprendizagem dos jovens são passiveis de outras análises que comunguem na busca de entender as desmotivações para apostar nas mudanças de vida a partir do estudo.

\section{Referências}

BRASIL. Constituição da República Federativa do Brasil. 1988. Brasília, DF: Senado, 1988 Disponível

em: <http://www.planalto.gov.br/ccivil_03/constituicao/ConstituicaoCompilado.htm>. Acesso em: 20 jun. 2018.

CARNEIRO, M. A. LDB Fácil: leitura crítico-compreensiva, artigo a artigo. Petrópolis: VOZES, 1998.

CARRANO, P.; DAYRELL, J.; MAIA, C. L. Juventude e ensino médio: sujeitos e currículos em diálogo. Belo Horizonte: Editora UFMG, 2014.

CASTRO, P. A. P. P.; TUCUNDUVA, C. C.; ARNS, E. M. A importância do planejamento das aulas para organização do trabalho do professor em sua prática docente. Athena, Rio Grande do Norte, v. 10, n. 10, p. 49-69, 2008.

DAYRELL, J. A escola "faz" as juventudes? Reflexões em torno da socialização juvenil. Educação e sociedade, Unicamp - SP, v. 28, n. 100, p. 1105-1128, 2007.

DAYRELL, J. T.; LEÃO, G.; REIS, J. B. dos. Jovens olhares sobre a escola do ensino médio. Cadernos Cedes, v. 31, n. 84, p. 253-273, 2011. 
KUENZER, A. Z.; GRABOWSKI, G. Educação Profissional: desafios para a construção de um projeto para os que vivem do trabalho. Perspectiva, v. 24, n. 1, p. 297-318, 2006.

KUENZER, A. Z. Ensino médio e profissionalização: as políticas do estado neoliberal. São Paulo: Cortez, 1997.

MEnegolla, M.; SANT’ANNA, I. M. Por que planejar? Como planejar? 10. ed. Petrópolis, RJ: Vozes, 2001.

PIAZZI, P. Aprendendo inteligência: manual de instruções do cérebro para alunos em geral. 2. ed. rev. São Paulo: Aleph, 2008. 